\title{
KAJIAN DAMPAK KAWASAN MANDIRI PANGAN DI PULAU TERLUAR PROVINSI ACEH
}

\author{
Helmi 1 dan Edy Marsudi2 \\ 1 Program Studi Ilmu Tanah, 2 Program Studi Agribisnis \\ Fakultas Pertanian Universitas Syiah Kuala
}

\begin{abstract}
ABSTRAK
Ketersediaan pangan secara makro tidak menjamin tersedianya pangan ditingkat mikro (rumah tangga penduduk). Produksi pertanian di lokasi tertentu pada musim panen, mengakibatkan terjadinya konsentrasi ketersediaan pangan di daerah produksi selama musim panen. Metode analisis data yang digunakan dalam kajian ini terdiri dari beberapa alat analisis yaitu : analisis deskriptif, analisis kelembagaan, analisis Comparative Performance Index (CPI) dan LFA (Logical Framework Analysis).

Identifikasi dampak program kawasan mapan yang menggunakan 6 instrumen dasar evaluasi yaitu instruktur, manajemen kelompok, permodalan, sarana prasarana, tenaga kerja dan teknologi serta penilaian terhadap dampak program menunjukkan Desa Suka Makmur berada pada peringkat pertama yang memiliki dampak terbesar dari Program Kawasan Mandiri Pangan terhadap masyarakatnya. Setelah itu disusul Desa Pulau Bengkalak berada pada peringkat kedua dan Desa Ujung Tinggi berada pada peringkat ketiga yang memiliki dampak program terhadap masyarakatnya.
\end{abstract}

Kata Kunci : Kawasan Mandiri

\section{PENDAHULUAN}

Ketersediaan pangan secara makro tidak menjamin tersedianya pangan ditingkat mikro (rumah tangga penduduk). Produksi pertanian di lokasi tertentu pada musim panen, mengakibatkan terjadinya konsentrasi ketersediaan pangan di daerah produksi selama musim panen. Pola konsumsi yang relatif sama diantara individu, antar waktu dan antar daerah, mengakibatkan adanya masa-masa paceklik dan lokasi-lokasi defisit pangan. Dengan demikian, mekanisme pasar dan distribusi pangan antar lokasi dan antar waktu dengan mengandalkan stok pangan, dapat berpengaruh terhadap keseimbangan antara ketersediaan dan konsumsi, serta berdampak pada harga yang terjadi di pasar. Faktor harga juga terkait dengan daya beli rumah tangga terhadap pangan. Meskipun bahan pangan tersedia di pasar, namun jika harganya tinggi serta daya beli rumah tangga rendah akan mengakibatkan rumah tangga tidak dapat mengakses bahan pangan yang ada di pasar. Kondisi ini memicu timbulnya kerawanan pangan.

Strategi untuk mewujudkan ketahanan pangan yaitu dengan melaksanakan kawasan mandiri pangan yang sudah dicanangkan oleh pemerintah dan keberhasilan kawasan tersebut sangat bergantung pada implementasi kawasan. Untuk mengukur keberhasilan kawasan desa mandiri pangan, maka sangat penting untuk melakukan analisis mengenai dampak desa mandiri pangan. Untuk mendorong terciptanya kondisi sosial ekonomi yang kondusif, menuju ketahanan pangan yang mandiri dan berkelanjutan.
Kajian ini bertujuan untuk menganalisis dan mengevaluasi keberdayaan masyarakat miskin perdesaan dalam mengelola dan memanfaatkan sumberdaya yang dimiliki atau dikuasainya secara optimal, untuk mencapai kemandirian pangan rumah tangga dan masyarakat.

\section{METODOLOGI KAJIAN Sumber Data}

Lokasi kajian ini berada di 3 pulau terluar, yaitu Pulau Siemeulue, Pulau Banyak Singkil dan Pulau Aceh Aceh Besar yang dilaksanakan sejak 1 September sampai dengan 30 November 2017. Data yang digunakan dalam kajian ini terdiri dari 2 jenis data yaitu data primer dan data sekunder, Berdasarkan data yang ada terdapat 22 desa dan 5 Kawasan Mandiri Pangan di 5 Kecamatan dan 3 Kabupaten di Provinsi Aceh Tahun 2017, yaitu: di Kecamatan Siemeulue Timur dan Kecamatan Teupah Selatan di Kabupaten Siemeulue; Kecamatan Pulau Banyak dan Kecamatan Pulau Banyak Barat di Kabupaten Singkil dan Kecamatan Pulau Aceh di Aceh Besar. Setiap kawasan akan dipilih satu desa sebagai desa sampel.

\section{Metode Analisis Data}

Metode analisis data yang digunakan dalam kajian ini terdiri dari beberapa alat analisis yaitu: analisis deskriptif, analisis kelembagaan, analisis Comparative Performance 
Index (CPI) dan LFA (Logical Framework Analysis).

\section{HASIL KAJIAN DAN PEMBAHASAN}

Gambaran Umum Kawasan Mandiri Pangan di Provinsi Aceh

Program kawasan mandiri pangan (Kamapan) adalah program nasional yang bertujuan untuk mengatasi kerawanan pangan dan kemiskinan di Indonesia. Pada awalnya 2006-2014 program ini diberi nama program desa mandiri pangan dan pada tahun 2015-2017 digabung beberapa desa namanya menjadi program kawasan mandiri pangan. Satu kawasan mandiri pangan terdiri dari 3-6 desa mandiri pangan. Pelaksanaan Program Kawasan di Provinsi Aceh dilaksanakan di desa rawan pangan dengan fokus kegiatan pemberdayaan masyarakat melalui 4 tahap, yaitu tahap persiapan, tahap penumbuhan, tahap pengembangan dan tahap kemandirian. Program Kawasan Mapan di Provinsi Aceh sudah berlangsung selama 3 tahun, di mulai pada tahun 2015 hingga sekarang ini tahun 2017. Adapun total jumlah Desa Mapan di Provinsi Aceh saat ini yaitu sebanyak 22 desa mapan yang tersebar di 3 wilayah Kabupaten antara lain Kabupaten Siemeulue, Kabupaten Singkil dan Kabupaten Aceh Besar. Secara rinci Kawasan mandiri pangan berdasarkan kabupaten di Provinsi Aceh dapat dilihat pada Tabel 1.

Tabel 1. Nama Desa Kawasan Mandiri Pangan di Provinsi Aceh Tahun 2015 - 2017

\begin{tabular}{|c|c|c|c|c|c|c|c|}
\hline No & Kabupaten & Kecamatan & Desa & Nama Kelompok & $\begin{array}{c}\text { Nama } \\
\text { Pendamping }\end{array}$ & $\begin{array}{c}\text { Jumlah } \\
\text { Angogota }\end{array}$ & $\begin{array}{c}\text { Nama Ketua } \\
\text { Kawasan }\end{array}$ \\
\hline 1 & 2 & 3 & 4 & 5 & 6 & 7 & 8 \\
\hline \multirow[t]{10}{*}{1} & Simeulue & Simeulue Timur & Ujung Tinggi & Sejahtera Umum & Edi Harta, S & 10 & Darul Hayjim \\
\hline & & & Pulau Siumat & Meita Tumáa & & 11 & \\
\hline & & & Kuala Makmur & Hidup Baru & & 10 & \\
\hline & & & Air Pinang & Bina Persada & & 12 & \\
\hline & & & Ganting & Subur & & 10 & \\
\hline & & Teupah Selatan & Pulau Bengkalak & Urep sarmo & Akhiruddin & 20 & Rasimudin \\
\hline & & & Lataling & Jaya Bura Indah & & 20 & \\
\hline & & & Anao & Samo Tajago & & 20 & \\
\hline & & & Blang Seubel & Sereta & & 21 & \\
\hline & & & Labuhan Bakfi & Suak Jaya & & 28 & \\
\hline \multirow[t]{7}{*}{2} & Singkil & Pulau Banyak Barat & Suka Makmur & Harapan Baru & Rafii & 17 & Ahmad Syaref \\
\hline & & & Haloban & Usaha Baru & & 17 & \\
\hline & & & Asantiola & Nelayan Putra & & 20 & \\
\hline & & & Ujung Sialit & Jasa Nelayan & & 21 & \\
\hline & & Pulau Banyak & Pulau Balai & Suka Damai & Khairl Anwar & 8 & Aman \\
\hline & & & Pulau Baguk & Suka Jaya & & 8 & \\
\hline & & & Teluk Nibung & Teluk Damai & & 8 & \\
\hline \multirow[t]{6}{*}{3} & Aceh Besar & Pulau Aceh & Seurepong & Mawar Putin & Abd. Razak & 20 & Asti \\
\hline & & & Gugop & Sarena & & 20 & \\
\hline & & & Ulee Paya & Makmu Beurata & & 20 & \\
\hline & & & Blang Siteungkoh & Bungong Jeumpa & & 20 & \\
\hline & & & Paloh & Bunot Jaya & & 20 & \\
\hline & 3 & 5 & 22 & 22 & & & \\
\hline
\end{tabular}

Sumber Data : Dinas Pangan Provinsi Aceh, Tahun 2017

Jumlah Program Kawasan mandiri pangan per tahun anggaran di Provinsi Aceh dapat dilihat pada Gambar 4. Berdasarkan data pada Gambar 4, trend. Jumlah program desa mapan per tahun anggaran di Provinsi Aceh dari tahun 2006 sampai tahun 2017 mengalami peningkatan yang cukup singnifikan.. Hal tersebut disebabkan karena pemerintah daerah Kabupaten tersebut menganggap desa-desa yang ada di daerahnya sudah memenuhi kriteria mapan.

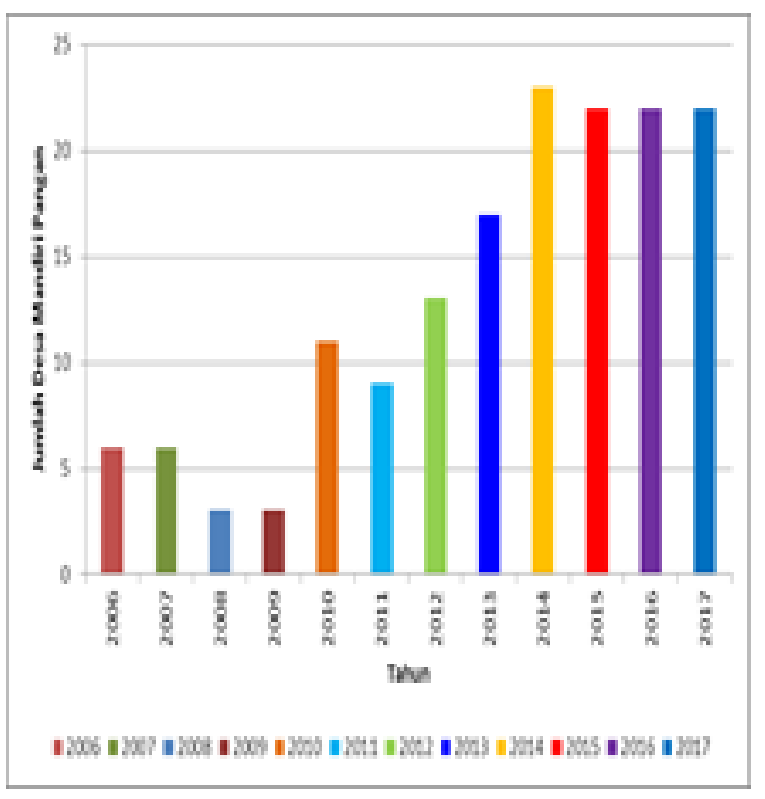

Gambar 4. Jumlah Program Desa Mandiri Pangan Per Tahun Anggaran di Provinsi Aceh, Tahun 2006 - 2017

\section{Identifikasi Dampak Program Kawasan Mandiri Pangan}

Identifikasi dampak program kawasan mapan yang dilakukan dalam penelitian ini menggunakan 6 instrumen dasar evaluasi yaitu instruktur, manajemen kelompok, permodalan, sarana prasarana, tenaga kerja dan teknologi. Penggunaan instrumen tersebut berdasarkan tingkat urgensi (kepentingan) dan sangat mudah dalam membantu peneliti untuk mengidentifikasi keberhasilan program desa mapan. Adapun bentuk penilaian terhadap instrumen evaluasi program desa mapan tersebut menggunakan skala likert. Instrumen dasar evaluasi program desa mapan dapat dilihat pada Tabel 4. 
Tabel 4. Instrumen Dasar Evaluasi Program Kawasan Mapan Tahun 2017

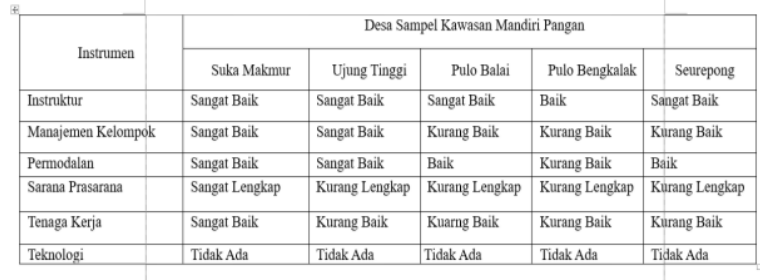

Berikut adalah hasil identifikasi dampak program desa mapan yang telah dilakukan di Provinsi Aceh, berdasarkan 6 instrumen dasar evaluasi yaitu infrastruktur, manajemen kelompok, permodalan, sarana prasarana, tenaga kerja dan teknologi.

\section{Instruktur}

Instruktur adalah salah satu pendukung yang sangat penting dalam keberhasilan Program kawasan mapan. Instruktur bertugas untuk melakukan kegiatan pendampingan dan memberikan penyuluhan kepada masyarakat yang menerima bantuan. Instruktur kawasan mapan yang ideal adalah penduduk setempat yang selama ini banyak terlibat dalam kegiatan sosial kemasyarakatan di desa. Selain itu juga dari track record pendidikannya pun harus mendukung yakni berbasis pertanian serta mempunyai kemampuan untuk memotivasi masyarakat dalam program pendampingan, dan yang lebih penting lagi adalah masyarakat percaya tentang tugas dan kemampuan instruktur tersebut. Instruktur yang ada di Desa Suka Makmur danDesa Ujung Tinggi termasuk kedalam kategori sangat baik karena latar belakang pendidikan yang tinggi dan merupakan penduduk asli yang sering melakukan kegiatan sosial kemasyarakatan di desa tersebut, sehingga sangat optimal dalam melakukan tugas-tugas pendampingan dan penyuluhan kepada masyarakat. Sedangkan instruktur yang berada di Ujung Tinggi termasuk kedalam kategori baik, walau memiliki latar belakang pendidikan yang tinggi namun bukan merupakan penduduk asli setempat, sehingga kurang optimal dalam melakukan kegiatan pendampingan dan memberikan penyuluhan kepada masyarakat.

\section{Manajemen Kelompok}

Proses manajemen dalam suatu kelompok organisasi sangat dibutuhkan untuk mempermudah pengelolaan sumberdaya yang tersedia. Sehingga sumberdaya tersebut dapat terdistribusi dengan baik dan benar sesuai dengan Standard Operasional Procedur (SOP) yang telah ditetapkan bersama. Manajemen kelompok yang dimaksud dalam instrumen evaluasi penelitian ini yaitu manajemen kelompok usaha yang dilaksanakan oleh kelompok penerima bantuan program dan teknis dalam menjalankannya. Manajemen kelompok pada Desa Ujung Tinggi dan Desa Bengkalak termasuk dalam kategori kurang baik, karena kurangnya rasa kepemilikan terhadap kelompok usaha yang dibentuk serta keseriusan dalam menekuni usaha yang dilakukan cukup rendah. Hal ini berdampak pada tidak berlanjutnya usaha yang dilakukan oleh kelompok usaha tersebut. Sedangkan manajemen kelompok pada Desa Suka Makmur termasuk dalam kategori sangat baik, karena rasa kepemilikan terhadap kelompok usaha dan keseriusan dalam menekuni usaha menyebabkan solidaritas diantara sesama petani cukup tinggi.

\section{Permodalan}

Program kawasan mapan memberikan bantuan modal kepada setiap kawasan rawan pangan sebesar Rp.200 juta. Dana tersebut disalurkan melalui Lembaga Keuangan Desa (LKD), kemudian diberikan kepada kelompokkelompok usaha yang dibentuk berdasarkan potensi sumberdaya alam dan sumberdaya manusia yang tersedia. Permodalan yang dimaksud dalam insturmen evaluasi kajian ini yaitu berupa sistem pengelolaan keuangan dan tingkat pengembalian modal.

Pengelolaan keuangan dan tingkat pengembalian modal di Desa Pulau Bengkalak termasuk kedalam kategori kurang baik. Hal ini disebabkan karena ada kelompok usaha yang usahanya gagal dan tidak dapat mengembalikan modal sesuai dengan target yang telah ditentukan. Selanjutnya pengelolaan keuangan dan tingkat pengembalian modal di Ujung Tinggi termasuk kedalam kategori baik. Walaupun ada beberapa kelompok usaha yang gagal namun masih dapat mengembalikan modal sesuai dengan target yang telah ditentukan.

\section{Sarana Prasarana}

Sarana prasarana sangat dibutuhkan bagi setiap daerah khususnya daerah yang rawan pangan. Sarana prasarana yang memadai dapat menunjang kehidupan dan kesejahteraan masyarakat menjadi lebih baik dan berkembang. Ketersediaan sarana prasarana dapat 
mempermudah mobilitas masyarakat desa dalam memasarkan hasil-hasil pertanian, mempermudah masyarakat dalam mengakses pangan, serta mempermudah masyarakat dalam memperoleh teknologi dan informasi yang mendukung inovasi pertanian. Sarana prasarana yang dimaksud dalam insturmen evaluasi penelitian ini yaitu berupa infrastruktur jalan pedesaan, kemudahan akses lokasi pedesaan, instalasi listrik, ketersediaan air bersih, fasilitas-fasilitas umum seperti sekolah, puskesmas, kantor pemerintahan (balai desa) dan transportasi umum.

\section{Tenaga Kerja}

Didalam bidang ekonomi tenaga kerja merupakan indikator penting bagi terlaksananya program pembangunan. Tenaga kerja yang dimaksud dalam insturmen evaluasi penelitian ini yaitu tingkat penyerapan tenaga kerja dan keberdayaan masyarakat dalam program desa mapan. Tingkat penyerapan tenaga kerja dan keberdayaan masyarakat di Desa Suka Makmur termasuk kedalam kategori sangat baik. Sedangkan di Desa Ujung Tinggi dan Desa Pulau Bengkalak tingkat penyerapan tenaga kerja dan keberdayaan masyarakatnya termasuk kedalam kategori baik.

\section{Teknologi}

Perkembangan ilmu pengetahuan dan teknologi pada saat ini begitu cepat dan sangat dinamis. Keberadaan ilmu pengetahuan dan teknologi sangat dibutuhkan dalam bidang pertanian dan ketahanan pangan. Teknologi yang dimaksud dalam instrumen evaluasi penelitian ini yaitu penerapan teknologi yang dilakukan kelompok usaha dalam melakukan inovasi produk yang dihasilkan.

\section{Penilaian Dampak Program Kawasan Mandiri Pangan}

Penilaian dampak program desa mapan dalam penelitian ini dilakukan dengan menggunakan teknik perbandingan indeks kinerja (Comparative Performance Index). Dampak program tersebut dapat dilihat dari seberapa besar pengaruh instrumen dasar evaluasi (infrastruktur, manajemen kelompok, permodalan, sarana prasarana, tenaga kerja dan teknologi) dapat dirasakan dan dinikmati oleh masyarakat desa mapan. Adapun Matriks Awal Penilaian Dampak Program Kawasan mandiri pangan dapat dilihat pada Tabel 5.
Tabel 5. Matrkis Awal Penilaian Dampak Program Desa Mapan, Tahun 2017

\begin{tabular}{|r|l|c|c|c|c|c|c|}
\hline \multirow{2}{*}{ No } & Desa Mapan & \multicolumn{6}{|c|}{ Kriteria } \\
\cline { 3 - 8 } & & INS & MNK & PMD & SPR & TKR & TEK \\
\hline 1 & Suka Makmur & 5 & 5 & 5 & 5 & 5 & 1 \\
\hline 2 & $\begin{array}{l}\text { Ujung Tinggi } \\
\text { Pulau Bengkalak }\end{array}$ & 4 & 3 & 3 & 5 & 4 & 2 \\
\hline 3 & Pulau Bengkalak & 5 & 3 & 4 & 5 & 4 & 1 \\
\hline 4 & Pulau Balai & 5 & 3 & 3 & 4 & 4 & 1 \\
\hline 5 & Seurepong & 4 & 3 & 3 & 4 & 4 & 1 \\
\hline \multicolumn{2}{|c|}{ Bobot Kriteria } & 0,20 & 0,15 & 0,20 & 0,15 & 0,15 & 0,15 \\
\hline
\end{tabular}

Sumber Data : Data Primer (diolah), Tahun 2017

Berdasarkan matriks awal penilaian pada Tabel 9 diatas, kriteria instrumen dasar evaluasi yaitu instruktur dilambangkan dengan INS, manajemen kelompok dilambangkan dengan MNK, permodalan dilambangkan dengan PMD, sarana prasarana dilambangkan dengan SPR, tenaga kerja dilambangkan dengan TKP dan teknologi dilambangkan dengan TEK. Bobot kriteria ditentukan langsung oleh peneliti berdasarkan tingkat kepentingan (urgensi) dari masing-masing instrumen dasar evaluasi. Sementara itu, angka kriteria dari masingmasing instrumen dasar evaluasi ditentukan dengan menggunakan skala likert. Hasil identifikasi kriteria yang dilakukan menunjukkan bahwa setiap instrumen dasar evaluasi memiliki trend positif (semakin tinggi nilainya semakin baik). Sehingga nilai minimum pada setiap kriteria instrumen dasar evaluasi ditransformasi ke-100, sedangkan nilai lainnya ditransformasi secara proporsional lebih tinggi. Matriks Hasil Transformasi Teknik Perbandingan Indeks Kinerja Penilaian Dampak Program Kawasan mandiri pangandapat dilihat pada Tabel 6 .

Tabel 6. Matrkis Hasil Transformasi Teknik Perbandingan Indeks Kinerja Penilaian Dampak Program Desa Mapan, Tahun 2017

\begin{tabular}{|c|l|r|r|r|r|r|r|r|r|}
\hline No & Desa Mapan & \multicolumn{6}{|c|}{ Kriteria } & Nilai & $\begin{array}{l}\text { Pering } \\
\text { kat }\end{array}$ \\
\cline { 3 - 11 } & & INS & MNK & PMD & SPR & TKR & TEK & & \\
\hline 1 & $\begin{array}{l}\text { Suka Makmur } \\
\text { Ujung Tinggi }\end{array}$ & 125 & 166,7 & 166,7 & 100 & 125 & 100 & 132,09 & \\
\hline 2 & $\begin{array}{l}\text { Ujung Tinggi } \\
\text { Pulau benkalak }\end{array}$ & 100 & 100 & 100 & 100 & 100 & 200 & 115,00 & \\
\hline 3 & Pulau Bengkalak & 125 & 100 & 133,3 & 100 & 100 & 100 & 111,66 & \\
\hline 4 & Pulau Balai & 110 & 100 & 115 & 100 & 100 & 100 & 106,30 & \\
\hline 5 & Seurepong & 107 & 100 & 112 & 100 & 100 & 100 & 104,20 & \\
\hline \multicolumn{2}{|c|}{ Bobot Kriteria } & 0,20 & 0,15 & 0,20 & 0,15 & 0,15 & 0,15 & & \\
\hline
\end{tabular}

Sumber Data : Data Primer (diolah), Tahun 2017 Berdasarkan matriks hasil transformasi pada Tabel 10 diatas, didapatkan total nilai indeks kinerja dari masing-masing desa mapan berturut-turut 
yaitu Desa Suka Makmur memiliki nilai indeks kinerja sebesar 132,09, Desa Ujung Tinggi memiliki nilai indeks kinerja sebesar 115,00 dan Desa Pulau Bengkalak memiliki nilai indeks kinerja sebesar 111,66. Artinya semakin besar nilai indeks kinerja suatu desa mapan maka semakin besar pula dampak program desa mapan yang dirasakan oleh masyarakat desa tersebut.

\section{KESIMPULAN DAN REKOMENDASI Kesimpulan}

1. Pelaksanaan Program Kawasan Mandiri Pangan di Provinsi Aceh dilaksanakan berturut turut selama 3 tahun sejak 2015, 2016 dan 2017 yang meliputi 4 tahapan pelaksanaan yaitu tahap persiapan, tahap penumbuhan, tahap pengembangan dan tahap kemandirian. Tahun 2015 merupakan tahap persiapan, Tahun 2016 merupakan tahap pertubumbuhan \& pengembangan dan Tahun 2017 tahap kemandirian.

2. Identifikasi dampak program kawasan mapan yang menggunakan 6 instrumen

dasar evaluasi yaitu instruktur, manajemen kelompok, permodalan, sarana prasarana, tenaga kerja dan teknologi serta penilaian terhadap dampak program menunjukkan Desa Suka Makmur berada pada peringkat pertama yang memiliki dampak terbesar dari Program Kawasan Mandiri Pangan terhadap masyarakatnya. Setelah itu disusul Desa Pulau Bengkalak berada pada peringkat kedua dan Desa Ujung Tinggi berada pada peringkat ketiga yang memiliki dampak program terhadap masyarakatnya.

3. Sistem kelembagaan Kawasan Mandiri Pangan di Desa Suka Makmur, Desa Pulau Bengkalak, dan Desa Ujung Tinggi melibatkan kegiatan lintas sektor yang dimulai dari Tim Pangan Desa, Kepala
Desa, Camat, Pokja Desa Mapan, Dinas/Unit Kerja Ketahanan Pangan.

4. Dampak program kawasan mandiri pangan di Provinsi Aceh dilihat dari manfaatnya yang dapat meningkatkan pangan dan gizi masyarakat, meningkatkan kesejahteraan masyarakat dan menyerap tenaga kerja. Sedangkan hasil (outcomes) yaitu tersedianya modal usaha, sarana dan prasarana semakin lengkap dan berkuranganya masyarakat miskin, dan output (keluaran) yang diperoleh adalah strategi pengembangan usaha yang terencana dan peningkatan produktivitas. Serta kegiatan (activities) yang dilakukan adalah dengan memberikan pelatihan, penyuluhan dan pendampingan yang intensif, menjalin kerjasama dengan universitas, perbankan dan swasta.

\section{Rekomendasi}

Berdasarkan hasil analisis permasalahan dan analisis dampak serta kesimpulan yang diperoleh maka dapat diberikan rekomendasi sebagai berikut:

1. Program Kawasan mandiri pangan masih tetap layak dilanjutkan untuk mengurangi angka kemiskinan di desadesa terluar atau kepulauan.

2. Agar kebijakan pemerintah yang mendukung dan berpihak kepada masyarakat dilakukan melalui peningkatkan SDM masyarakat desa dengan memberikan pelatihan, penyuluhan dan pendampingan yang intensif serta kemudahan akses usaha bagi masyarakat.

3. Terus melakukan pelatihan bagi pendamping, FKK dan LKK khususnya dalam pengelolaan administrasi kelompok dan penyusunan RencanaUsaha Kelompok (RUK)

\section{DAFTAR PUSTAKA}

BKP. 2012. Pedoman Desa Mandiri Pangan. Badan Ketahanan Pangan Kementerian Pertanian RI. Jakarta. 
BKP. 2015. Rencana Strategis Badan Ketahanan Pangan 2015-2020. Kementerian Pertanian Jakarta.

BKP. 2015. Pedoman Umum Kawasan Mandiri Pangan. Badan Ketahanan Pangan Kementerian Pertanian RI. Jakarta.

BKP. 2015. Pedoman Umum Program Aksi Desa Mandiri Pangan. Menuju Gerakan Kemandirian Pangan. Kementerian Pertanian RI. Jakarta.

BKP. 2012. Pedoman Umum Peningkatan Diversifikasi dan Ketahanan Pangan Masyarakat. Badan Ketahanan Pangan Kementerian Pertanian. Jakarta.

BPS. 2015. Indikator Kesejahteraan Rakyat. Badan Pusat Statistik, Jakarta.

Darwis Valeriana dan Rusastra I.W. 2011. Optimalisasi Pemberdayaan Masyarakat Desa Melalui Sinergi PUAP dengan Desa Mandiri Pangan. Jurnal : Analisis Kebijaskan Pertanian, Volume 9 No 2 Juni 2013, Halaman 125-142 Pusat Sosial Ekonomi dan Kebijakan Pertanian Badan Litbang Pertanian Kementerian Pertanian, Bogor

Fahrudin, A. 2012. Pengantar Kesejahteraan Sosial. Universitas Padjajaran, Bandung

Jamhari. 2012. Analisis Tingkat Ketahanan Pangan Rumah Tangga di Provinsi

Jawa Tengah. Prosiding Seminar Nasional Hasil Penelitian Sosial

Ekonomi Pertanian Universitas Gadjah Mada, Yogyakarta. ISBN 978-979971-149-3-0

Kaemba, GA. 2013. Kebijakan Pemerintah Desa dalam Pelaksanaan Program Nasional Pemberdayaan Masyarakat Mandiri. Jurnal Eksekutif. Puslitbang Kementerian Pertanian RI, Jakarta

Marimin dan Maghfiroh N. 2012. Aplikasi Teknik Pengambilan Keputusan Dalam Manajemen Rantai Pasok. IPB Press. Bogor.

Mulyono, A. 2008. Studi Partisipasi Masyarakat pada Program Desa Mandiri Pangan di Desa Muntuk, Kabupaten Bantul. Universitas Diponegoro, Semarang.

Nasdian, FT. 2014. Pemgembangan Masyarakat. Bogor[ID]: Yayasan Pustaka Obor Indonesia. Jakarta
Ratnasari M dan Priharsdoyo B. 2009.

Faktor-Faktor yang Mempengaruhi

Kerawanan Pangan Rumah Tangga

Miskin Di Desa Wiru Kecamatan

Bringin Kabupaten Semarang. Jurnal Jejak Volume 2 Nomor 2.

Suharto, E. 2015. Membangun Masyarakat Memberdayakan Rakyat. Didalam: Refika Aditama.Garjita, I., Susilowati, I., \& Retnaningsih, T. 2014. Strategi Pemberdayaan Masyarakat Kelompok Tani Hutan Ngudi Makmur di Sekitar Kawasan Taman Nasional Gunung Merapi. UNS Yogyakarta.

Septiasari, MI., Diarta, IKS., \& Dewi, RK. 2013. Perbandingan antara Pendapatan Rumah Tangga Petani di Subak Daerah Pariwisata dan Non Pariwisata. Jurnal Agribisnis dan Agrowisata, Universitas Udayana, Denpasar.

Siregar, K., Lubis, S., \& Emalisa. 2013. Dampak Program Desa Mandiri Pangan Terhadap Tingkat Pendapatan Masyarakat (Studi Kasus: Kelurahan Ladang Bambu, Kecamatan Medan Tuntungan). Fakultas Pertanian USU, Medan

Soemarno. 2015. Strategi Pemenuhan Kebutuhan Pangan Rumah Tangga Petani.

Tulisan Ilmiah. Jurusan Tanah FPUB.

Ostrom, E. (1990). Governing of the common. The Evolution of Institutions for

Collective Action. Cambridge University Press.

Qoriah, S. N. et. al. 2008. Analisis Gender Dalam Program Desa Mandiri Pangan, Studi Kasus Desa Jambakan, Kecamatan Bayat, Klaten, Jawa Tengah. Jurnal : Transdisiplin Sosiologi, Komunikasi dan Ekologi Manusia, Halaman 209-234. Agustus 2008 